\title{
ALVES, Alessandro Cavassin. A província do Paraná e a sua Assembleia Legislativa (1853-1889): a forca política das famílias tradicionais. Curitiba: Máquina de Escrever, 2015. 496p.
}

\author{
Ana Crhistina Vanali ${ }^{1}$
}

- Enviado em 27/01/2016
- Aprovado em 03/02/2016

O livro “A província do Paraná e a sua Assembleia Legislativa (1853-1889): a força das famílias tradicionais" de autoria de Alessandro Cavassin Alves ${ }^{2}$ nos apresenta como as velhas famílias senhoriais do período colonial formaram os novos clãs eleitorais do período imperial no Paraná. Os dados empíricos levantados e analisados mostra como se deu a formação de uma intricada e visível rede familiar que passou a exercer o poder político local. Os representantes políticos da recém instalada província do Paraná estavam atrelados a uma estrutura familiar, por nascimento ou por casamento, que garantia a sua eleição e a manutenção dessa rede de parentes no poder.

Ao identificar as principais famílias que compunham a classe política paranaense no período imperial são identificados também os principais líderes políticos (que o autor chama de chefes ostensivos que eram os articuladores políticos) de acordo com o partido político dominante - liberal ou conservador. $\mathrm{O}$ autor faz uma análise profunda e detalhada mostrando como o poder executivo (presidente de província indicado pelo imperador D.Pedro II), o poder legislativo no âmbito nacional (deputados gerais) e no âmbito local (deputados provinciais), além dos cargos de primeiro escalão (juiz de paz, delegados, inspetores da educação, etc) sempre agiam em sintonia com o poder

\footnotetext{
${ }^{1}$ Doutoranda em Sociologia pela Universidade Federal do Paraná. Endereço eletrônico: anacvanali@yahoo.com.br
}

${ }^{2} \mathrm{O}$ presente livro é resultado da tese em Sociologia defendida pelo autor em 2014 no Programa de Pós-Graduação em Sociologia da UFPR. A versão na íntegra está disponível na Biblioteca Digital da UFPR http://dspace.c3sl.ufpr.br/dspace/bitstream/handle/1884/35972/R\%20-\%20T\%20-

$\%$ 20ALESSANDRO\%20CAVASSIN\%20ALVES.pdf? sequence=1. 
central e que os representantes eleitos sempre eram de famílias tradicionais ou estavam de alguma forma vinculadas à elas.

O livro está dividido em 4 capítulos e cada capítulo corresponde a análise de uma década dos 36 anos de história imperial do Paraná. Para cada década, o autor fornece um quadro com a composição dos membros (eleitos e suplentes) de cada legislatura da Assembleia Legislativa Provincial, além de dados complementares de cada deputado provincial (idade, partido, residência, ocupação e comissão na qual atuou) e um outro quadro com a relação de todas as leis aprovadas em cada legislatura. O estudo biográfico e genealógico realizado pelo autor das 188 personalidades políticas do Paraná durante o período imperial nos demonstra de maneira bastante clara como a política paranaense "nasceu" e se manteve (e se mantém) baseada na rede familiar.

No primeiro capítulo é analisada a década de 1850 marcada pela criação e instalação da Província do Paraná e pela conciliação entre liberais e conservadores. É nessa década que ocorre a estruturação do corpo eleitoral do Paraná. A nova província tem uma vaga para o senado e está foi ocupada pelo Barão de Antonina (João da Silva Machado), do Partido Conservador, de 1854 até seu falecimento em 1875 (lembrando que o cargo de senador nessa época era vitalício). Com relação à participação na Assembleia Legislativa Geral, o Paraná tinha duas vagas a partir da 9a legislatura. Essas vagas foram inicialmente ocupadas por Antonio Candido Ferreira de Abreu (conservador) e Jesuíno Marcondes de Oliveira e Sá (liberal). Nessa década ocorreu a instalação da Assembleia Legislativa Provincial e as três primeiras legislaturas são apresentadas nesse capítulo. O autor já destaca nesse capítulo quais são os três clãs eleitorais mais influentes que marcam toda a política paranaense do período imperial: os Guimarães e Correia, os Sá Ribas e os Oliveira e Sá e Alves Araújo. Analisando os deputados províncias dessa década: dos 47 eleitos, 34 eram parentes próximos.

No segundo capítulo é analisada a década de 1860 marcada pela atuação das lideranças liberais. São analisadas da $11^{\mathrm{a}}$ a $14^{\mathrm{a}}$ legislaturas da Assembleia Legislativa Geral e da $5^{\mathrm{a}}$ a $8^{\mathrm{a}}$ legislaturas da Assembleia Legislativa Provincial - todas marcadas pela composição familiar pois o núcleo duro não mudou e continuava sendo dominado por membros dos três clãs eleitorais mais influentes apresentados no capítulo anterior. Nessa década temos o episódio denominado de "cardosadas" que foi como ficou conhecido o período de gestão do presidente da província do Paraná José Francisco Cardoso por ter tomado medidas que desagradaram a classe política paranaense tradicional, limitando o poder dessas famílias políticas durante as eleições. Assim, os grandes clãs eleitorais perdem espaço para outras famílias que começam a participar da vida política 
do Paraná, mas mesmo assim, dos 60 deputados provinciais eleitos nessa década, 27 eram dos clãs tradicionais, destacando o clã Oliveira e Sá e Alves e Araújo que elegeram novos parentes. Os outros deputados eleitos que não pertenciam diretamente à parentela das famílias tradicionais não estavam fora do círculo restrito do poder familiar.

No terceiro capítulo é analisada a década de 1870 marcada pela atuação das lideranças conservadoras. São analisadas as $15^{\mathrm{a}}$ e $16^{\mathrm{a}}$ legislaturas da Assembleia Legislativa Geral e da $9^{\mathrm{a}}$ a $13^{\mathrm{a}}$ legislaturas da Assembleia Legislativa Provincial - todas marcadas pelos poderosos grupos familiares já apresentados nos capítulos anteriores. As mesmas famílias tradicionais permanecem no núcleo duro da política paranaense. Nessa década, no ano de 1875, faleceu o senador do Paraná, o Barão de Antonina e em seu lugar assume Manuel Francisco Correia, o segundo senador do Paraná do período imperial, cujo mandato vai de 1877 a 1889. Nesse capítulo o autor nos apresenta o Quarteto Saquarema do Paraná (conservadores) composto por Manoel Antonio Guimarães (Visconde de Nácar) e seus cunhados Manoel Francisco Correia e Manoel Eufrásio Correia, além de Agostinho Ermelino de Leão e o Quarteto Luzia (liberais) do Paraná composto por Jesuíno Marcondes de Oliveira e Sá, Antonio Alves de Araújo, Manoel Alves de Araújo e Generoso Marques dos Santos. Apesar da rixa política entre liberais e conservadores o autor nos mostra vários casos onde houveram casamentos entre membros do partido conservador com sobrinhas, netas, irmãs e filhas de membros do partido liberal e ao contrário também. Assim, o núcleo duro da Assembleia Legislativa Provincial permanecia estável sendo comandado pelas mesmas famílias desde a sua instalação em 1854. Dos 63 deputados eleitos nessa década, 33 pertenciam a um dos três clãs centrais da política paranaense e 50\% desses deputados era parentes diretos entre si.

No quarto e último capítulo é analisada a década de 1880 marcada pela composição de liberais e conservadores. São analisadas da $17^{\mathrm{a}}$ a $20^{\mathrm{a}}$ legislaturas da Assembleia Legislativa Geral e da $14^{\mathrm{a}}$ a $18^{\mathrm{a}}$ legislaturas da Assembleia Legislativa Provincial. Sendo a liderança exercida pelos liberais ou pelos conservadores, na prática nada modificava, pois, o núcleo duro da Assembleia Legislativa Provincial continuava baseado na estrutura familiar dos três principais clãs eleitorais. $\mathrm{O}$ autor aponta alguns políticos que tiveram pouca expressão no período imperial, mas que se tornaram grandes figuras com o regime republicano como o caso de Francisco Xavier da Silva e Vicente Machado. É nessa década que ocorre a nomeação do primeiro paranaense como presidente da província do Paraná - João José Pedrosa. Até então, os outros paranaenses foram nomeados vice-presidentes. João José Pedrosa foi uma exceção nessa estrutura onde a "parentela se reunia para governar" pois, segundo o autor seu acesso ao poder se deu através de "seus estudos e 
qualidades pessoais" - ele não fazia parte de nenhuma família tradicional do Paraná, e não se casou com ninguém dessas famílias, mas foi colega de turma do curso de Direito em São Paulo de vários membros descendentes das famílias tradicionais do Paraná como Silveira da Mota e Generoso Marques, representantes da classe dominante tradicional. Outros "outsiders" são destacados pelo autor como Trajano Reis, Tertuliano Teixeira de Freitas e Justiniano de Mello e Silva, que não eram membros das famílias tradicionais do Paraná, mas que conseguem entrar para a política local e a partir de seus filhos já estão na intrincada estrutura familiar paranaense. O autor também faz a análise dos membros da Assembleia Legislativa Provincial que eram de origem de famílias de imigrantes e que por meio do casamento são inseridos na estrutura de poder local. Resultado: na última legislatura da assembleia provincial, dos 24 deputados eleitos e mais um suplente, apenas 2 não pertenciam às famílias tradicionais paranaenses e a tese do autor fica comprovada: o cargo de deputado provincial era restrito a membros das famílias tradicionais, "todos" que ocuparam esse cargo durante o período imperial no Paraná estavam ligados às poucas famílias de sesmeiros dos séculos XVII. Os poucos que não estavam vinculados a essa intricada rede familiar foram as exceções para confirmarem a regra. Não importava se a liderança estava com os liberais ou com os conservadores - todos pertenciam às famílias tradicionais do Paraná. Durante as legislaturas provinciais o Paraná não escolheu nenhum deputado republicano, mostrando a sintonia da política local com a orientação do gabinete imperial. Às vésperas da implantação da república a política paranaense continuava nas mãos das antigas e tradicionais famílias paranaenses. Na década de 1880 dos 71 deputados eleitos 17 vinham de legislaturas anteriores e 28 pertenciam a um dos três principais clãs eleitorais. Os demais eram parentes distantes entre si. Com a implantação da República desaparecem os quartetos saquarema e luzia e em seu lugar a política do Paraná fica dividida entre as figuras de Generoso Marques e de Vicente Machado.

O livro é um estudo prosopográfico dos políticos eleitos no Paraná e pelo Paraná durante os 36 anos da história imperial paranaense. Através de um estudo minucioso da documentação e dos periódicos da época, da reconstituição genealógica, da análise da frequência com que políticos foram eleitos e quem ocupava os principais cargos na assembleia provincial o autor identificou os três principais clãs eleitorais do período comandados por seus chefes ostensivos e demonstrou como o exercício do núcleo duro da política paranaense se revezava entre esses três clãs eleitorais de acordo com a linha política ideológica do gabinete imperial ora liberal, ora conservador. Ao final é fornecido um quadro biográfico dos 188 políticos eleitos nesse período o que complementa o estudo de Francisco Negrão sobre a genealogia paranaense que aponta apenas 156 políticos citado no livro analisado. Dos 31 políticos eleitos no Paraná durante o período imperial e não citados por Francisco 
Negrão, o autor comprava que 25 deles faziam parte das antigas famílias tradicionais paranaenses. O restante foram casos de deputados eleitos com algum interesse específico e que são analisados pelo autor como os deputados André Rebouças e Henrique de Beaurepaire Rohann. Em suma, a parentela estava reunida para governar e os políticos que se revezavam no poder e nos altos cargos administrativos de acordo com o poder central do Rio de Janeiro faziam parte de uma intricada rede familiar. Hoje, século XXI, na formação do quadro político paranaense ainda encontramos pessoas herdeiras desses clãs eleitorais, das tradicionais famílias paranaenses que remonta ao século XVII ressaltando a importância do estudo da família e da genealogia como categorias de análise na compreensão da realidade social numa perspectiva de longa duração. 